\title{
Responsabilidade Municipal pela Prestação do Serviço de Oxigenoterapia Domiciliar e Seus Contornos ${ }^{(*)}$
}

\author{
MUNICIPAL LIABILITY FOR THE PROVISION OF DOMICILIARY \\ OXYGEN THERAPY SERVICE AND RELATED MATTERS
}

Luciano Moreira de Oliveira ${ }^{(* *)}$

\section{RESUMO}

O presente trabalho busca aplicar, no âmbito do direito à saúde, as premissas do neoconstitucionalismo, interpretando o referido direito a partir dos objetivos constitucionais. $\mathrm{O}$ artigo analisa a responsabilidade do município na prestação do serviço de oxigenoterapia domiciliar e sua extensão, tendo por orientação os princípios da dignidade da pessoa humana, integralidade e resolutividade. Finalmente, o trabalho descreve a iniciativa adotada pelo Ministério Público no município de Bom Despacho (MG) para assegurar a observância de tais princípios.

\section{Palavras-chave}

Direitos Fundamentais; Direito à Saúde; Ministério Público; Neoconstitucionalismo; Oxigenoterapia domiciliar.

\section{ABSTRACT}

This work intends to apply the premises of neoconstitutionalism to the right to health, interpreting such right according to the purposes of the Cons-

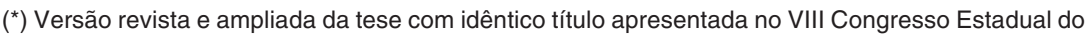
Ministério Público do Estado de Minas Gerais, realizado nos dias 4 a 6 de junho de 2008, na cidade de Diamantina/MG. Aprovada por unanimidade.

$\left({ }^{* *}\right)$ Promotor de Justiça do Estado de Minas Gerais, pós-graduando em Direito Sanitário pela Escola de Saúde Pública de Minas Gerais — ESP/MG. E-mail: <lucianolmo@ @mp.mg.gov.br>. Recebido em 18.7.08. Aprovado em 7.10.08. 
titution. It analyzes the municipal liability for the provision of domiciliary oxygen therapy service based on the principles of human dignity, integrality and resolution. Finally, it describes the initiative undertaken by the State Prosecutors Office in the municipality of Bom Despacho, State of Minas Gerais, Brazil, to enforce such principles.

\section{Keywords}

Domiciliary Oxygen Therapy; Fundamental Rights; Neoconstitutionalism; Right to Health; State Prosecutors Office.

\section{INTRODUÇÃO}

A promulgação da Constituição de 1988 constitui marco histórico para a mudança de postura da doutrina do Direito Constitucional no país. Com efeito, a partir de então, encontrou eco no Brasil o movimento já vivenciado na Europa do neoconstitucionalismo, que firmou posição em favor da força normativa da Constituição, conferindo novo prestígio e fôlego para o Direito Constitucional, buscando deslocar o epicentro do ordenamento jurídico do Código Civil para a Constituição.

Na Europa, a reconstitucionalização dos estados no segundo pós-guerra contou com vozes como a de Konrad Hesse, que passaram a utilizar como premissas para a análise dos textos constitucionais o reconhecimento do caráter vinculativo e obrigatório de suas disposições, ou seja, a imperatividade das normas constitucionais ${ }^{(1)}$.

De seu turno, a Constituição de 1988 revelou-se terreno fértil para o desenvolvimento do novo direito constitucional no Brasil. Partindo do pressuposto de sua força normativa, a doutrina passou a revisitar antigos conceitos e realizou novas análises com base nos supostos do neoconstitucionalismo.

Nesse contexto, admite-se que a interpretação adequada das normas constitucionais deve "concretizar, de forma excelente, o sentido (Sinn) da proposição normativa dentro das condições reais dominantes numa determinada situação"(2). Outrossim, reconhecendo-se a supremacia material da Constituição e a normatividade dos seus princípios ${ }^{(3)}$, percebeu-se que a

(1) BARROSO, Luís Roberto. Neoconstitucionalismo e constitucionalização do direito. Revista de Direito Constitucional e Internacional, ano 15, n. 58, p. 129-143, jan./mar. 2007.

(2) HESSE, Konrad. A força normativa da Constituição. Tradução: Gilmar Ferreira Mendes. Porto Alegre: SAFE, 1991. p. 22-23.

(3) ALEXY, Robert. Sistema jurídico, principios jurídicos y razón práctica. Disponível em: <http:// www.cervantesvirtual.com/portal/DOXA/index.shtml>. Acesso em: 28 out. 2007. 
mesma irradia seus efeitos para todo o ordenamento jurídico, razão pela qual a análise de antigos institutos está sendo refeita em consonância com a Constituição (filtragem constitucional) ${ }^{(4)}$.

Em se tratando de direitos fundamentais, o pano de fundo do neoconstitucionalismo e sua premissa de força normativa da Constituição, foram acompanhados da previsão constante do art. 5ำ $\S 1^{\circ}$ inserto no texto constitucional, que dispõe que "as normas definidoras dos direitos e garantias fundamentais têm aplicação imediata". Nesse sentido, doutrina e jurisprudência têm admitido de forma recorrente a exigibilidade de prestações estatais destinadas à concretização de direitos fundamentais, independentemente de intermediação legislativa, livrando o direito constitucional do descrédito de outrora.

As considerações realizadas até o momento mostram-se imprescindíveis para a análise do tema proposto, uma vez que se insere no âmbito do direito à saúde, que foi reconhecido como direito fundamental pela Constituição de 1988, como se denota do enunciado do art. 6º , onde está ao lado dos chamados direitos sociais.

Em face de todo o exposto, percebe-se que ao direito à saúde deve ser aplicado o regime jurídico concernente aos demais direitos fundamentais e, por decorrência, o disposto no art. 5으 $\S 1^{\circ}$ o da Constituição. Mais. Tratando-se de direito assegurado na Constituição e que conta com detalhada normativa em seu texto - em especial, Seção II, Capítulo II, do Título VIII — impõe-se a análise das situações fáticas, concretizando referido direito em consonância com a orientação constitucional.

Neste ponto, cumpre ressaltar que a concretização dos direitos previstos na Constituição - e como tal, do direito à saúde - é tarefa atribuída ao Ministério Público. Com efeito, o redesenho pelo qual passou a instituição na Constituição de 1988 deve ser atribuído aos anseios da sociedade por um órgão independente e autônomo, que pudesse evitar que o direito se tornasse apenas uma carta de intenções.

No tocante à saúde, pode-se afirmar, com toda a segurança, que o Ministério Público é instituição vocacionada para tirar o direito da abstração e concretizá-lo. Inicialmente, o art. 127 dispõe que incumbe ao Ministério Público a defesa dos interesses sociais e individuais indisponíveis. De outro lado, o art. 129, II estabelece como função institucional do Ministério Público "zelar pelo efetivo respeito dos Poderes Públicos e dos serviços de relevância pública aos direitos assegurados nesta Constituição, promovendo as medidas necessárias a sua garantia." Tal disposição encontra eco no art. 197, que estabelece que as ações e serviços de saúde são de relevância pública. Outrossim, o art. 129, III atribui ao Ministério Público a possibilidade de promover o inquérito civil e a ação civil pública para a defesa de direitos difusos e coletivos, como de regra se caracteriza a saúde.

(4) BARROSO, Luís Roberto. op. cit., p. 151. 
Dessa forma, conforme se demonstrará a seguir, incumbe ao Ministério Público tomar as medidas necessárias para a garantia do serviço de oxigenoterapia domiciliar às pessoas que dele necessitarem, concretizando o direito à saúde e cumprindo sua vocação constitucional.

\section{DA OXIGENOTERAPIA DOMICILIAR}

\section{Da necessidade da terapêutica e responsabilidade por sua prestação}

A oxigenoterapia pode ser definida como qualquer forma de fornecimento de oxigênio com o intuito terapêutico, podendo ser dividida em duas vertentes. A primeira refere-se às pessoas que se encontram em situação de risco iminente de morte, como nos casos de insuficiência respiratória, parada cardiorrespiratória, coma ou choque. De outro lado, há indicação para fornecimento em terapia de longo prazo - condições crônicas -, normalmente em caráter domiciliar, como ocorre com os portadores de fibrose cística e doença pulmonar obstrutiva crônica, entre outros ${ }^{(5)}$.

Os usuários do Sistema Único de Saúde - SUS - que necessitam da oxigenoterapia domiciliar, como dito, são portadores de condições crônicas em virtude das quais apresentam um quadro de hipoxemia (baixa de oxigênio no sangue).

Trata-se de casos em que o uso do oxigênio será prolongado, necessário para o suporte da vida e garantia de bem-estar dos pacientes para os quais é prescrito. Saliente-se que, em grande parte das vezes, trata-se de terapêutica a ser utilizada por idosos, donde se conclui a aplicabilidade dos dispositivos da Lei n. 10.741/03.

Utilizado na forma terapêutica, o oxigênio é considerado um fármaco, que deve ser prescrito segundo evidências apontadas cientificamente ${ }^{(6)}$. Sua utilização reduz a morbi-mortalidade dos usuários para os quais é prescrito, devendo a terapia domiciliar ser prestada para aquelas pessoas que, a despeito de tal necessidade, não tenham indicação para internação hospitalar ${ }^{(7)}$.

(5) FRAGA, Alexandre Resende. Relatório 005/2003 do Centro de Apoio Operacional à Execução do Ministério Público do Estado de Minas Gerais. Procedimento administrativo n. 02/2003. 2ª Promotoria de Justiça de Defesa da Saúde da Comarca de Belo Horizonte/MG. p. 13-14.

(6) As indicações de uso apontadas são Pa02 menor ou igual a 55 ou saturação menor ou igual a $88 \%$, consoante FRAGA, Alexandre. op. cit. Além destas, o programa de oxigenoterapia do Estado de Minas Gerais acrescenta $\mathrm{PaO} 2$ menor que 60 e maior que 55 ou saturação menor que $89 \%$, havendo policitemia (hematrócito maior que 55\%) e/ou sinais clínicos, radiológicos e eletrocardiográficos de cor pulmonale crônico.

(7) Dentre os objetivos do programa de oxigenoterapia domiciliar do Estado de Minas Gerais estão "retirar o pneumopata crônico do ambiente hospitalar, visando a melhoria da qualidade de vida dos mesmos e a liberação dos leitos hospitalares, ocupados por pacientes com necessidade exclusiva de oxigenoterapia", conforme dispõe o art. 1ำ do programa, aprovado pela resolução conjunta SES/ SEPLAG n. 5592/2003. 
A prestação adequada da oxigenoterapia domiciliar, segundo apontam os técnicos, possibilita:

(...) diminuir o número de internações hospitalares, melhorar a qualidade de vida do paciente, diminuir os custos da assistência para o Sistema Único de Saúde (SUS), além de manter o paciente no seu domicílio junto dos seus familiares, fazendo com que o cidadão permaneça em seu município de residência. ${ }^{(8)}$

Pelo exposto até o momento, vê-se que não há dúvida quanto à existência de indicação técnica para a prestação de oxigenoterapia domiciliar. Trata-se de serviço imprescindível para a manutenção e melhoria da saúde da pessoa para a qual é prescrito.

Com isso, conclui-se que incumbe ao Poder Público organizar e executar o serviço de oxigenoterapia domiciliar para as pessoas que do mesmo necessitarem, segundo critérios apontados pela ciência atual. Inquestionável que encontra amparo no texto da Constituição, por ser medida necessária à saúde, direito fundamental que goza de aplicabilidade imediata (art. 6oㅡ, c/c art. 5을 $\S 1^{\circ}$ da CR/88).

Examinando o texto da Constituição, percebe-se que o desempenho de ações e serviços públicos de saúde constitui responsabilidade solidária dos entes federados $^{(9)}$, nos termos do art. 23, II, art. 30, VII e art. 196, todos da $\mathrm{CR} / 88$. Igualmente, saliente-se que o pacto pela saúde, firmado por representantes dos entes federados e constante da Portaria GM/MS n. 399/2006 dispõe como obrigações dos entes da federação responder pela integralidade da assistência à saúde.

Nada obstante, o art. 198, I da CR/88 estabelece como diretriz do SUS a descentralização. Desdobrando referido princípio, o art. 7º, IX, "a" da Lei n. 8.080/90 define a "ênfase na descentralização dos serviços para os municípios". Por sua vez, o art. 18, I da citada Lei n. 8.080/90 estabelece como competência da direção municipal do SUS "planejar, organizar, controlar e avaliar as ações e os serviços de saúde e gerir e executar os serviços públicos de saúde" (grifou-se).

(8) ZEFERINO, Maria Terezinha. Diretrizes para oxigenoterapia domiciliar. São Paulo: Segmento Farma Editores, 2004. p. 13. Disponível em: <http://www.saude.sc.gov.br/oxigenoterapia>. Acesso em: 21 abr. 2008.

(9) Referido posicionamento tem sido reiteradamente manifestado pelos tribunais pátrios e é ilustrado pelo seguinte aresto: "No que toca ao direito do cidadão à saúde e à integridade física, a responsabilidade do Município é conjunta e solidária com a dos Estados e a da União. Tratando-se de responsabilidade solidária, a parte necessitada não é obrigada a dirigir seu pleito a todos os entes da federação, podendo direcioná-lo àquele que Ihe convier. O Sistema Único de Saúde, tendo em vista o seu caráter de descentralização, torna solidária a responsabilidade pela saúde, alcançando a União, os Estados e os Municípios." (TJMG — Apelação n. 1.0145.06.308228-6/001(1) — Rel. Des. Heloisa Combat. Julgamento em 13.11.2007. DJ 28.03.2008) 
Percebe-se, portanto, que, em que pese a reconhecida responsabilidade solidária dos entes federativos, a execução dos serviços de saúde compete ao município, devendo contar com a cooperação da União e do Estado (art. 30, VII da CR/88, art. 16, XIII e art. 17, III, ambos da Lei n. 8.080/90).

Dessa forma, incumbe ao município prestar o serviço de oxigenoterapia domiciliar aos usuários do SUS que dele necessitarem, segundo critérios técnicos.

Considerando que se trata de medida imprescindível para o suporte da vida e garantia de bem-estar do usuário, reduzindo a morbimortalidade daqueles para os quais a terapia é indicada, incumbe ao Ministério Público, instituição vocacionada para a concretização do direito à saúde, adotar as medidas necessárias para a garantia da prestação adequada do serviço àqueles que possuírem indicação(10).

\section{Das formas de prestação}

A oxigenoterapia domiciliar pode ser dispensada de três maneiras: por meio de oxigênio líquido, cilindros ou aparelhos concentradores de oxigênio, sendo estas duas as formas mais comuns de dispensação(11).

Os cilindros de oxigênio, também conhecidos como "balas", apresentam como vantagens a possibilidade de armazenamento por longos períodos, sem perdas, bem como o fato de existirem pequenos cilindros que podem ser transportados no caso de locomoção. No entanto, têm custo variável, regra geral são grandes, pesados, e se requer cuidados na guarda e manuseio, uma vez que não podem sofrer quedas ${ }^{(12)}$.

De seu turno, os aparelhos concentradores de oxigênio possuem custo fixo e a produção de oxigênio é ilimitada, tratando-se de equipamentos de fácil manuseio ${ }^{(13)}$. A nosso juízo, conferem maior autonomia para os usuários, por contarem com o equipamento sempre à sua disposição, sendo desnecessárias trocas e reposições. Contudo, apresentam fluxo máximo de 5

(10) Saliente-se que referida iniciativa foi tomada pela Promotora de Justiça com atribuição perante a $2^{\text {a }}$ Promotoria de Justiça de Defesa da Saúde de Belo Horizonte. Foi proposta ação civil pública em face do município de Belo Horizonte - Autos n. 0024.03.092513-5 - , que foi julgada procedente e transitou em julgado em 19.05.2006. No âmbito do Ministério da Saúde, reconheceu-se ser devida a assistência ventilatória aos usuários portadores de distrofia muscular progressiva, cabendo aos Estados e Municípios em gestão plena a identificação dos pacientes que necessitam da ventilação intermitente, bem como cadastrar serviços de saúde que possam realizar a manutenção e acompanhamento domiciliar destes pacientes e à viabilização deste tipo de assistência (Portarias GM/MS ns. 364/2001 e 1431/2001).

(11) Nesse sentido ZEFERINO, Maria Terezinha. op. cit., p. 33.

(12) Id., loc. cit.

(13) Id., loc. cit. 
litros/min, necessitam de energia elétrica para funcionarem e é recomendável a disponibilidade de cilindro para os casos de eventual interrupção no fornecimento de energia elétrica(14).

Certo é que não há evidências de que um tipo de prestação seja tecnicamente superior à outra. Ambas dispõem de respaldo científico e não há registros de contraindicações clínicas para uma ou outra forma.

Percebe-se, portanto, que há mais de uma maneira de atender o interesse público, com igual respaldo técnico. Assim, a eleição da forma de prestação do serviço de oxigenoterapia domiciliar se situa na esfera da discricionariedade administrativa, cabendo ao gestor do SUS a eleição daquela que, no caso concreto e segundo seu crivo, seja mais indicada ${ }^{(15)}$.

\section{Extensão da responsabilidade pela prestação da oxigenoterapia domiciliar}

Como já dito, a prestação de oxigenoterapia domiciliar é um serviço de saúde que deve ser organizado e prestado pelos municípios, por ser indispensável para a manutenção e melhora do estado de saúde das pessoas que possuem hipoxemia crônica, conforme evidências científicas.

Neste ponto, deve-se destacar que a prestação de um serviço eficaz, que atenda às necessidades do usuário do SUS, é dever do Poder Público, que se justifica à luz do princípio da dignidade da pessoa humana (art. 1ํㅡㄴ III da $\mathrm{CR} / 88$ ). Ainda que dispensável, a imposição de que tal serviço seja apto para fazer frente às necessidades do usuário encontra amparo em dois princípios do SUS: integralidade e resolutividade.

A integralidade está exposta no art. 198, II da CR/88, que estabelece como diretriz do SUS o atendimento integral. De seu turno, o art. 6o, I, "d", incluiu no âmbito do SUS a execução de ações de assistência terapêutica integral, inclusive farmacêutica.

Contudo, a conceituação do referido princípio encontra-se no art. 7ํㅡ, II, entendendo-se como "conjunto articulado e contínuo das ações e serviços preventivos e curativos, individuais e coletivos, exigidos para cada caso em todos os níveis de complexidade do sistema".

É possível perceber que o princípio da integralidade está intrinsecamente ligado à resolutividade, prevista no art. $7^{\circ}$, XII da Lei n. 8.080/90, que preconiza a "capacidade de resolução dos serviços em todos os níveis de

(14) ZEFERINO, Maria Terezinha, op. cit., p. 33.

(15) Não se afasta, aqui, a possibilidade de análise da motivação e a verificação da razoabilidade da decisão. 
assistência". Segundo as promotoras de justiça Dilma Jane, Josely Pontes e Maria de Lurdes Santa Gema, exige-se que "quando um indivíduo busca um atendimento ou quando surge um problema de impacto coletivo sobre a saúde, o serviço correspondente esteja capacitado para enfrentá-lo e resolvê-lo até o nível de sua competência"(16).

Ora, a toda evidência, somente é possível admitir que o Poder Público se desincumbiu de seu dever previsto no art. 196 da CR/88 se prestou serviço que atenda ao usuário na integralidade e seja resolutivo. Impossível admitir "meio-tratamento" ou tratamento ineficaz, o que violaria, em última análise, o princípio da dignidade da pessoa humana.

Em face do exposto, deve-se afirmar que a garantia da prestação da oxigenoterapia domiciliar não se limita à disponibilidade de concentrador ou cilindro de oxigênio. Isso porque se trata de um serviço de saúde que, como tal, deve estar capacitado para atender às demandas dos usuários.

Nesse sentido, está incluída na responsabilidade do Poder Público a disponibilidade de equipe de saúde para a realização de visitas aos usuários e verificar seu estado, bem como adotar os procedimentos cabíveis no caso de intercorrências. Por óbvio, deve haver a disponibilidade de técnicos para realizar a manutenção dos equipamentos, o que, de qualquer forma, deve ocorrer regularmente ${ }^{(17)}$.

Segundo o citado Programa de Oxigenoterapia Domiciliar do Estado de Minas Gerais, estabelecido pela Resolução conjunta n. 5.592/2003, emitida pela Secretaria de Estado da Saúde - SES - e Secretaria de Estado de Planejamento e Gestão - SEPLAG, incumbe aos municípios, entre outras responsabilidades, oferecer assistência aos usuários com necessidade de oxigenoterapia domiciliar, independentemente de fornecer-lhes ou não o aparelho; manter equipe de profissionais para acompanhamento da utilização do aparelho pelo usuário, constituída por assistente social e enfermeira ou auxiliar de enfermagem; realizar visitas domiciliares, no máximo, a cada sessenta dias; bem como garantir o acesso dos usuários aos exames necessários, tudo nos termos do art. 5ํㅜ do programa.

Maior discussão envolve a responsabilidade pelos custos de energia elétrica, quando se elege o concentrador de oxigênio como meio para a prestação do serviço. Isso porque o equipamento acarreta drástica elevação dos custos com fornecimento de energia elétrica ${ }^{(18)}$. Penaliza-se, extremamente, a

(16) SANTOS, Dilma Jane Couto Carneiro; PONTES, Josely Ramos; SANTA GEMA, Maria de Lurdes Rodrigues. Manual do Curador da Saúde. Belo Horizonte: Imprensa Oficial, 2002. p. 24.

(17) Em regra, referida incumbência fica a cargo da empresa contratada para o fornecimento dos aparelhos.

(18) No município de Bom Despacho/MG, foi implantado programa de oxigenoterapia domiciliar por meio de aparelhos concentradores de oxigênio. O modelo de aparelho cedido, se ligado 24 horas, durante 30 dias, acarreta o consumo de $324 \mathrm{Kwh}$. 
população mais carente, uma vez que, além da elevação consumo, ocorre a perda de isenção fiscal e dos descontos destinados a consumidores de baixa renda, uma vez que há limite de consumo para se gozar de tais benefícios ${ }^{(19)}$.

Neste ponto, cumpre ratificar que a eleição da forma de prestação da oxigenoterapia domiciliar - oxigênio líquido, concentrador ou cilindro - é matéria afeta à discricionariedade administrativa. Nada obstante, eleita uma das formas de prestação, deve-se assegurar assistência integral e resolutiva.

Assim, caso se eleja a prestação de oxigenoterapia domiciliar por meio de concentrador, incumbe ao município arcar com os custos da energia elétrica necessária para seu funcionamento. Pensar o contrário é violar os princípios da integralidade e resolutividade, admitindo que o usuário receba "meio-tratamento", incapaz de atender as suas necessidades ${ }^{(20)}$.

\section{ATUAÇÃO DO MINISTÉRIO PÚBLICO NO MUNICÍPIO DE BOM DESPACHO/MG}

No município de Bom Despacho/MG, foi implantado, no segundo semestre de 2007, programa de oxigenoterapia domiciliar, que passou a ser oferecida por meio de concentrador de oxigênio. Organizou-se o serviço, estabelecendo protocolo de admissão do usuário, no qual foram definidos critérios de inclusão e exclusão baseados em evidências científicas.

Antes da organização atual do serviço, o município disponibilizava a assistência ventilatória por meio de cilindros de oxigênio. Com a substituição pelos concentradores de oxigênio, os usuários do serviço afirmaram que estavam impossibilitados de arcarem com os custos de energia elétrica decorrentes do uso dos aparelhos. O tratamento estava se tornando inviável e ainda existia o risco de suspensão do fornecimento da energia.

Diante de tal quadro, o Ministério Público propôs ação civil pública com o escopo de responsabilizar o município pelo pagamento decorrente do uso do concentrador de oxigênio. Todavia, o pedido de antecipação de tutela foi indeferido.

(19) Segundo a Resolução n. 485/2002, da ANEEL, o benefício da tarifa social para consumidores residenciais de baixa renda requer que o consumo mensal esteja entre 80 e $220 \mathrm{Kwh}$. A isenção de ICMS, em Minas Gerais, limita-se ao consumo mensal de até 90 kwh.

(20) Saliente-se que já houve precedente, relativo à demanda individual, que contou com a acolhida do TJMG, conforme demonstra o acórdão a seguir: Reexame necessário. Ação ordinária com pedido de tutela antecipada. Assistência médica. Menor que necessita da utilização de equipamentos médicos (Respirador ST/D30, Oxímetro Mod. 1000 e Base Aquecida) para sobreviver, eis que sofre de insuficiência respiratória grave. Porém, apesar de dispor dos equipamentos médicos em sua residência, não dispõe de condições financeiras para arcar com os gastos de energia elétrica gerados pela utilização de referidos aparelhos (cerca de $204 \mathrm{KWh} / \mathrm{mês}$ - $R \$ 100,00$ ao mês). Dever do Município de prestar a assistência necessitada pela menor. Problema médico que demanda recursos e providências razoáveis e possíveis de serem fornecidos pelo Município. (TJMG - Reexame necessário - Autos n. 1.0024.04.360754-8/001(1) — Rel. Des. Jarbas Ladeira. Julgamento em 25.04.2006. DJ 02.06.2006). 
Decidiu-se, então, de forma pioneira, pela elaboração de Termo de Compromisso de Ajustamento de Conduta - TAC - , que foi proposto ao município de Bom Despacho e à concessionária do serviço de fornecimento de energia elétrica, CEMIG Distribuição S/A.

Após tratativas, o município reconheceu ser sua a responsabilidade pelos custos de energia elétrica decorrentes do uso do concentrador. De outro lado, consultando-se a CEMIG, verificou-se que a alternativa técnica mais adequada para operacionalizar o acordo seria o cálculo do consumo mensal de energia do concentrador de cada usuário, o que pode ser feito levando-se em conta a potência do equipamento e o número de horas diárias de tratamento que é prescrito. A partir deste, tal consumo seria deduzido do gasto total da residência onde se encontra o usuário e atribuído ao município, na fatura do mesmo.

Disciplinou-se o pacto entre o Ministério Público, município de Bom Despacho/MG e a CEMIG em TAC, sendo estabelecido o dever do município de arcar com o consumo de energia elétrica de todos os usuários do programa municipal que fosse referente à utilização do aparelho concentrador de oxigênio na forma acima exposta. A CEMIG assumiu o compromisso de ajustar seus sistemas para viabilizar o ajuste. Além disso, ficou definido que os usuários do programa seriam cadastrados como clientes especiais para possuírem prioridade no restabelecimento do fornecimento de energia elétrica em caso de falha técnica, bem como adotar todas as cautelas devidas antes de eventual suspensão no fornecimento por inadimplência do consumidor referente ao seu consumo próprio de energia ${ }^{(21)}$. Finalmente, ficou ajustado que apenas o consumo próprio da residência seria utilizado como parâmetro para verificação da incidência de ICMS e do benefício da tarifa social.

A assinatura do TAC foi aprovada pelo Conselho Municipal de Saúde, como já havia sido o programa de oxigenoterapia domiciliar, sendo autorizada a despesa por lei municipal.

Após, solicitou-se a homologação do TAC com relação às obrigações assumidas pelo Ministério Público e o município de Bom Despacho/MG e à extinção do processo referente à ação civil pública ajuizada, nos termos do art. 269, III do CPC(22).

(21) Em caso de inadimplência do município no que se refere à parte do consumo cujo custo é de sua responsabilidade, ficou vedada a suspensão do fornecimento de energia elétrica para o usuário do programa de oxigenoterapia domiciliar.

(22) É necessário salientar que o custo da medida para o orçamento municipal pode ser classificado como reduzido, sobretudo à vista da sua relevância e benefício social. Segundo informações da Secretaria Municipal de Saúde de Bom Despacho, a locação dos aparelhos concentradores de oxigênio custa $\mathrm{R} \$ 120,00$ (cento e vinte reais) por mês, por usuário. Outrossim, o aparelho concentrador de oxigênio, se utilizado 24 horas por dia - o que não ocorre em todos os casos - , consome 324 Kwh por mês de energia, que custa R $\$ 222,06$. Finalmente, deve-se destacar que Bom Despacho é um município que conta com cerca de 43 mil habitantes e dispõe, no momento, em torno de 25 usuários do programa de oxigenoterapia. 
Atualmente, o acordo realizado está sendo cumprido com o devido êxito.

\section{CONSIDERAÇÕES FINAIS}

A Constituição de 1988 é o marco histórico do neoconstitucionalismo no Brasil. A partir de então, a força normativa da Constituição, a imperatividade de suas normas e o caráter normativo e vinculante dos princípios constitucionais são premissas utilizadas pela doutrina para análise dos institutos jurídicos.

A Constituição de 1988 consagra a saúde como direito fundamental, que goza, portanto, de exigibilidade imediata (art. $5^{\circ}, \S^{\circ} 1^{\circ}$ ) e tem como uma das instituições vocacionadas para exigir sua concretização o Ministério Público.

A oxigenoterapia domiciliar deve ser prestada aos usuários do SUS que, em decorrência de enfermidade, possuem hipoxemia crônica, conforme preconizam as evidências científicas.

O serviço de oxigenoterapia domiciliar deve ser prestado pelo município, que poderá contar com cooperação do Estado ou da União, uma vez que compete ao mesmo gerir e executar os serviços públicos de saúde, nos termos do art. 18, I da Lei n. 8.080/90.

A prestação de oxigenoterapia domiciliar não se resume à disponibilidade do meio para se obter o oxigênio. À luz dos princípios da integralidade e resolutividade, deve o Poder Público prestar serviço de saúde capacitado para atender às necessidades do usuário do SUS.

Nesse sentido, deve o município arcar com os custos da energia elétrica necessária para a utilização do aparelho concentrador de oxigênio, quando eleita esta forma de organização do serviço, sob pena de se privar o usuário do acesso à terapêutica. Referido custo está incluído na prestação do serviço de oxigenoterapia domiciliar.

Sendo dever do Ministério Público "zelar pelo efetivo respeito dos Poderes Públicos e dos serviços de relevância pública aos direitos assegurados pela Constituição, promovendo as medidas necessárias a sua garantia”, devese adotar as providências necessárias para que o serviço de oxigenoterapia domiciliar seja prestado aos usuários do SUS, de forma integral e resolutiva.

\section{REFERÊNCIAS BIBLIOGRÁFICAS}

ALEXY, Robert. Sistema jurídico, principios jurídicos y razón práctica. Disponível em: <http://www.cervantesvirtual.com/portal/DOXA/index.shtml>. Acesso em: 28 out. 2007. 
BARROSO, Luís Roberto. O direito constitucional e a efetividade de suas normas. 8. ed. São Paulo: Renovar, 2006.

Neoconstitucionalismo e constitucionalização do direito. Revista de Direito Constitucional e Internacional, ano 15, n. 58, p. 129-173, jan./mar. 2007.

FRAGA, Alexandre Resende. Relatório 005/2003 do Centro de Apoio Operacional à Execução do Ministério Público do Estado de Minas Gerais. Procedimento administrativo no 02/2003. 2ª Promotoria de Justiça de Defesa da Saúde da Comarca de Belo Horizonte/MG.

HESSE, Konrad. A força normativa da Constituição. Tradução: Gilmar Ferreira Mendes. Porto Alegre: SAFE, 1991.

SANTOS, Dilma Jane Couto Carneiro; PONTES, Josely Ramos; SANTA GEMA, Maria de Lurdes Rodrigues. Manual do Curador da Saúde. Belo Horizonte: Imprensa Oficial, 2002.

ZEFERINO, Maria Terezinha. Diretrizes para oxigenoterapia domiciliar. São Paulo: Segmento Farma Editores, 2004. Disponível em: <http://www.saude.sc.gov.br/ oxigenoterapia>. Acesso em: 21 abr. 2008. 